\title{
Desenvolvendo habilidades para um atendimento clínico humanizado: relato de uma experiência na disciplina de Semiologia Médica
}

\section{PALAVRAS-CHAVE}

- Educação Médica.

- Educação de Graduação em Medicina

- Estágio Clínico

\section{KEY WORDS}

- Medical Education.

- Medical Education, Undergraduate

- Clinical Clerkship.

Developing skills for humanistic patient care: an experience in the graduate course in basic clinical skills

Sebastião Soares Leal ${ }^{\mathrm{I}}$ Maria Mônica Freitas Ribeiro ${ }^{\mathrm{I}}$

\section{R E S U M O}

A utilização da expressão livre, com estímulo à criatividade, é apresentada como um método para o aprendizado das habilidades de comunicação e para a reflexão sobre a relação médico-paciente na disciplina de Semiologia Médica. O desenvolvimento dos trabalhos em grupo pelos estudantes estimula a reflexão e a criatividade sobre a atividade vivenciada nos ambulatórios e possibilita o exercício do trabalho em equipe.

\section{A B S T R A C T}

The article presents free expression with encouragement for creativity as a method for learning communications skills and reflecting on the physician-patient relationship in the course on Clinical Skills. The development of group projects by students encourages reflection and creativity on their experience in the outpatient clinics and allows exercising teamwork.

\section{Recebido em: 08/06/2009}


Este artigo relata uma experiência didática na disciplina de Semiologia Médica, que introduz o aluno no aprendizado da clínica.

A disciplina de Semiologia, na Faculdade de Medicina da Universidade Federal de Minas Gerais, tem como objetivo o ensino-aprendizagem de técnicas de entrevista médica, exame físico geral e relação médico-paciente. Com carga horária de 60 horas, no decorrer de 15 semanas, ela envolve o atendimento clínico de pacientes de primeira consulta e os subsequentes retornos. Os atendimentos se dão no ambulatório, em grupos de cinco alunos, em média, sob a supervisão/orientação do professor médico.

O curso é iniciado com duas aulas introdutórias que permitem preparar os alunos para o atendimento feito individualmente, sem a intervenção dos colegas ou do professor. Nesta introdução descreve-se o método, situam-se os alunos no contexto que lhes é estranho, criando-se um espaço onde expõem suas dúvidas e apreensões. Fica patente a ansiedade que os domina ante uma experiência nova e de grande responsabilidade. Essa é uma oportunidade única para prepará-los para a nova fase do curso médico.

Salienta-se, nesta fase, o potencial que cada um traz e a oportunidade de o grupo resgatar todo o saber/conhecimento que tem, adquirido nas duas décadas de vida e em cerca de 15 anos de ensino formal, desde o pré-escolar, bem como todo o saber que a vida lhes deu: o viver em si mesmo, a convivência em família e em sociedade, a literatura, o cinema, o teatro, a mídia.

A atitude do professor no sentido de fazer despertar nos alunos este valioso patrimônio os encoraja, instando-os a praticarem essencialmente os valores indispensáveis à relação médico-paciente. Estes valores são confrontados e compartilhados com os dos colegas e os do professor. Tais valores e princípios serão aplicados no objetivo final, que é desenvolver habilidades para um atendimento clínico humanizado.

Esta atitude, ou atitudes, permeia o processo de ensino-aprendizagem, especialmente num curso em que sobressai a necessidade de aquisição e desenvolvimento de habilidades psicomotoras e psicoafetivas. Neste sentido, cabe assinalar o que diz Carvalho (p. 25-6) ${ }^{1}$ :

O ensino - pelo viver nos educamos. O meio exterior nos vai fornecendo, dia a dia, situações-estímulo que, por nós percebidas, apercebidas e reelaboradas, vão paulatinamente alterando, para melhor, nossas ideias, nossos sentimentos e nossos atos. Infelizmente, também esse mesmo ambiente pode apresentar-nos situações-estímulo negativas, que se transformam, dentro de nós, em experiências deseducativas, levando-nos a formular falsas ideias, estruturando preconceitos, impulsionando-nos a agir de forma pouco construtiva - ou mesmo destrutiva - ou ainda gerando, em nossa sensibilidade, sentimentos e emoções que prejudicam o desenvolvimento harmônico de nosso ser ou nosso eficiente ajustamento aos meios físico, social e cultural. Essas experiências, educativas ou não, podem provir de pessoas as mais diversas e de situações as mais variadas. Uma conversa, um livro, um filme, uma peça teatral, uma notícia na imprensa, uma carta, um telefonema, um programa de televisão podem ter esse poder de nos afetar, de nos modificar. Como, porém, o meio social deseja que aprendamos certas ideias, que dominemos certas técnicas e que estruturemos certas atitudes, para bem desempenharmos nossos papéis nos diversos grupos a que pertencemos - grupos familiar, profissional, religioso, político, etc. -, surge então o ensino, ou seja, o esforço educativo deliberado, consciente, sistematizado [...].

Carvalho (p.29) ${ }^{1}$ igualmente pontua:

Aprendizagem é um termo que tanto se aplica ao processo de aprender quanto ao seu resultado. Há quem procure estabelecer uma distinção terminológica, denominando o processo de aprendizado e guardando a palavra aprendizagem para as consequências do processo. [...] A aprendizagem, encarada como o resultado do processo de aprender, redunda na modificação do comportamento do educando. Aprender é modificar o comportamento - por meio do treino e da experiência - visando a alcançar uma resposta melhor e mais adequada às situações-estímulo que se nos apresentam. Essa modificação do comportamento abrange alterações na maneira de pensar, de sentir e de agir.

Aprender é tornar possível para si próprio, na mesma medida em que ensinar é mostrar que é possível.

Ao lado destas considerações iniciais, recorremos a uma passagem nos escritos de Freire (p. 21) ${ }^{2}$.

A sociedade nos atribui, e assumimos, uma série de papéis nos quais podemos nos comportar de diferentes maneiras. Nestes papéis somos livres para exercitar nossa liberdade e, portanto, criar um modo diferente de viver, ou para seguir os padrões que a sociedade impõe. Só temos estes dois caminhos, já que não podemos fugir dos papéis. Somos pais ou filhos, votamos, aprendemos ou ensinamos, somos amantes, etc., queiramos ou não. A nossa escolha se coloca entre seguir as ordens da sociedade, e portanto sermos cúmplices dela, ou fazer tudo de modo a atender às necessidades de realização de nossa liberdade e assim concretizar agora nossos sonhos, nossa utopia.

Ao longo de nossa experiência docente na faculdade, sentimos necessidade de aprimorar o ensino da Semiologia, procu- 
rando individualizar não só o paciente, mas também o aluno e enfatizar o trabalho em grupo com foco no atendimento ético e humanizado.

Assim, recorremos nos últimos 12 anos a um método que tem se mostrado muito eficiente: a identificação das potencialidades de cada aluno e sua expressão como grupo.

Temos recorrido à criatividade, quando o grupo apresenta o resultado de sua aprendizagem ao final do curso, utilizando formatos variados: monografia, audiovisual, jornal, revista, peça teatral, jogos, etc. A proposta é apresentada à turma no início do semestre e desenvolvida de acordo com a escolha de cada grupo de alunos, ao longo do período, sem interferência do professor, que toma conhecimento do trabalho no momento da apresentação.

Esta iniciativa tem proporcionado um ganho que se confirma pela qualidade dos trabalhos apresentados. No contexto do atendimento clínico, têm sido abordados temas diversos - da técnica do exame físico à discussão sobre o papel do acompanhante durante a consulta, das angústias geradas pelo fazer médico ao crescimento percebido no decorrer da disciplina, passando pelo exercício profissional vivenciado com os pacientes na sua prática de estudantes -, todos eles fruto de percepção e reflexão próprias sobre aspectos marcantes escolhidos para a apresentação. Sem dúvida, dependendo do formato de apresentação escolhido, este já é, por si só, um momento muito rico para o professor e os alunos. Podemos citar como exemplos as apresentações dos últimos semestres, nas quais sobressaiu a encenação de um atendimento clínico pelo grupo de alunos, que, propositadamente, assumiam condutas éticas e técnicas inadequadas na condução do atendimento, seguidas por uma discussão pelo grupo. Outro recurso utilizado foi a apresentação de vídeos de consultas simuladas feitas de acordo com a abordagem centrada no paciente, com discussão de seus vários aspectos pela turma. Uma forma criativa de apresentação foi a confecção de um jogo, em que as respostas permitiam avançar ou recuar em direção ao objetivo, de acordo com os erros ou acertos. Todos esses trabalhos foram apresentados sob a supervisão do professor, que participou ativamente das discussões.

Já há algum tempo, os estudiosos de ensino médico têm buscado meios de desenvolver habilidades e sensibilidade para o exercício da medicina por meio das artes, para favorecer o desenvolvimento de empatia, capacidade de relacionamento e narrativa $^{3}$. Trabalhos que utilizam a literatura destacam a importância de seu estudo para a discussão da ética médica ${ }^{4}$. As artes plásticas, com visitas a museus orientadas por professores de arte, têm sido utilizadas para aprimorar a capacidade de obser- vação ${ }^{5}$. Também o uso de jogos como promotores de interesse no estudo $^{6}$ tem sido relatado como facilitador da aprendizagem.

A apresentação, de forma livre e criativa, das habilidades e atitudes requeridas para o atendimento clínico tem se revelado um excelente exercício. Tem sido possível observar o desenvolvimento da capacidade de reflexão do aluno, com enfoque na percepção do outro como um ser humano. Além disso, é vivenciado o trabalho em equipe, habilidade essencial para o desempenho profissional nos tempos atuais.

A elaboração de trabalhos criativos possibilita ao aluno vivenciar uma experiência de trabalho coletivo, com a manifestação de criatividade e habilidades individuais, e ao professor, o conhecimento claro da compreensão técnica do aluno e seu manejo das habilidades adquiridas. Obtém-se, portanto, não só a aplicação da teoria, mas, especialmente, "como" o aluno a utiliza, explicitando seu potencial humano e o investimento afetivo lançado na clínica. Vale ressaltar a boa receptividade a esta iniciativa, refletida no envolvimento com os trabalhos e na qualidade destes.

\section{REFERÊNCIAS}

1. Carvalho IM. O processo didático. Rio de Janeiro: FGV Ed.; 1972.

2. Freire R, Brito F. Utopia e Paixão: a política do cotidiano. Rio de Janeiro: Rocco; 1987.

3. Shapiro J, Rucker L, Beck J. Training the clinical eye and mind: using the arts to develop medical students' observational and pattern recognition skills. Med Educ. 2006;40(3):263-268.

4. Jones AH. Narrative based medicine: Narrative in medical ethics. BMJ. 1999;318:253-256.

5. Bardes CL, Gillers D, Herman A. Learning to look; developing clinical observational skills at an art museum. Med Educ. 2001;35(12):1157-1161.

6. Meterissians S, Liberman M, McLeod P. Games as teaching tools in a surgical residency. Med Teach. 2007;29(9):e258-e260.

\section{CONTRIBUIÇÃO DOS AUTORES}

Os autores participaram de forma suficiente na elaboração do artigo, assim como da redação do texto e revisão da versão final.

O artigo foi elaborado pelos dois autores, a partir da reflexão sobre a experiência com o método de avaliação descrito e busca de bibliografia sobre o tema e resultou de trabalho conjunto. 


\section{CONFLITO DE INTERESSES}

Declarou não haver.

ENDEREÇO PARA CORRESPONDÊNCIA

Maria Mônica Freitas Ribeiro
Av. Professor Alfredo Balena, 190 -sl. 246

Centro - Belo Horizonte

CEP. 30130 -100 - MG

E-mail: mmonica@medicina.ufmg.br 